\title{
Influência de fatores bioclimáticos nos índices produtivos e fisiológicos de caprinos nativos confinados ${ }^{1}$
}

\author{
Jackson R. de S. Leite ${ }^{2}$, Dermeval A. Furtado ${ }^{3}$, Antônio F. Leal ${ }^{3}$, \\ Bonifácio B. Souza ${ }^{4} \&$ Andrea S. da Silva ${ }^{5}$
}

\begin{abstract}
RESU M 0
O bjetivou-se neste trabalho determinar os fatores bioclimáticos e seus efeitos sobre os índices fisiológicos e produtivos de caprinos nativos confinados na região do Cariri paraibano. Utilizaram-se 36 animais, machos não-castrados, 12 por grupo genético, quais sejam: Moxotó, Azul e Graúna, com peso médio de $16,6 \pm 1,7 \mathrm{~kg}$, distribuídos em delineamento inteiramente casualizado, em arranjo fatorial $3 \times 5$ (três raças e cinco horários de observação). Os fatores ambientais foram coletados através de um sistema eletrônico de aquisição de dados modelo CR1000. Para avaliação dos parâmetros fisiológicos foram aferidas temperatura retal, frequência respiratória e a temperatura superficial, três dias por semana, das 6 às $18 \mathrm{~h}$, com intervalo de três horas cada uma. 0 s índices bioclimáticos foram elevados a partir das 12 $\mathrm{h}$, atingindo valores críticos às $15 \mathrm{~h}$, caracterizando situação de desconforto térmico. Os animais mantiveram a temperatura retal dentro dos limites normais porém com aumento da frequência respiratória. A temperatura superficial foi semelhante entre as raças. Os animais da raça Graúna apresentam maior ganho de peso diário e maior ganho de peso no período experimental, quando comparada com as outras raças estudadas.
\end{abstract}

Palavras-chave: adaptabilidade, bioclimatologia animal, estresse térmico

\section{Thermal comfort parameters of native goats raised in confinement in the semiarid of Paraíba state}

\begin{abstract}
AB STRACT
The objective of this w ork was to determine the thermal comfort indexes and their effects on physiological parameters of native goats raised in confinement in the Cariri region of Paraíba state. In this study 36 noncastrated male animals, were used, 12 per genetic group, which were Moxotó, Azul and Graúna, with an average weight of $16.6 \pm 1.7 \mathrm{~kg}$, distributed in a completely randomized design in $3 \times 5$ factorial arrangement (three breeds and five observation times). The studied environmental data were collected by an electronic data acquisition model CR1000. To evaluate the physiological parameters rectal temperature, respiratory frequency and surface temperature were measured three days a week from 6 a.m to 6 p.m with an interval of three hours. Environmental parameters increased from $12 \mathrm{~h}$ to reach critical values at 3 p.m, characterizing a situation of thermal discomfort. The animals could maintain a rectal temperature within normal limits, but with increasing respiratory frequency. The superficial temperature did not very among races. The animals of breed Graúna presented higher daily weight gain during the experimental period in comparison to other breeds.
\end{abstract}

Key words: adaptability, animal bioclimatology, thermal stress

\footnotetext{
${ }^{1}$ Parte da Dissertação de Mestrado do primeiro autor apresentada à COPEAG/U AEA/U FCG. Financiada pela CAPES/CN Pq 2 Mestre em Engenharia Agrícola. CEP 58798-000, N ova Olinda, PB. Fone: (83) 34591058. E-mail: jrs_leite@ hotmail.com 3 U FCG. CEP 58109-180, Campina Grande, PB. Fone: (83) 2101-1055. E-mail: dermeval@ deag.ufcg.edu.br; leal@deag.ufcg.edu.br ${ }^{4}$ DMV/UFCG. CEP 58700-970, Patos, PB. Fone: (83) 3511-3048. E-mail: bonifacio@pq.cnpq.br

${ }^{5}$ M estre em Zootecnia. CEP 58397-000. Areia, PB. Fone: (83) 3362-2300. E-mail: deazoo@hotmail.com
} 


\section{INTRODUÇÃO}

Os caprinos, tal como outros mamíferos, são amimais homeotérmicos, ou seja, apresentam a capacidade de controlar, dentro de uma pequena margem, a temperatura interna do corpo, mecanismo este eficaz quando a temperatura ambiente está dentro de certos limites, o que demonstra a importância de se manter as instalações com temperaturas ambientais próximas às das condições de conforto (Santos et al., 2005; Souza et al., 2005; Silva et al., 2010) Para reduzir os efeitos do estresse pelo calor pode-se utilizar algumas estratégias de manejo ambiental, em que as instalações zootécnicas devem visar ao controle de fatores climáticos, principalmente a temperatura ambiente, que leva ao desconforto térmico.

Os índices de conforto térmico foram desenvolvidos para caracterizar ou quantificar as zonas de termoneutralidade, adequadas às diferentes espécies animais apresentando, em uma única variável, tanto os fatores que caracterizam o ambiente térmico que circunda o animal, como o estresse que o ambiente lhe possa estar causando. No desenvolvimento de um índice de conforto térmico são levados em conta os fatores meteorológicos relevantes para a criação de certo animal e, se ressalta o peso que cada fator possui dentro desse índice, conforme sua importância, relativa também ao animal (Perissinoto et al., 2005).

Segundo Baccari Júnior et al. (1996), a avaliação da relação básica entre os animais e seu ambiente térmico começa com a zona de termoneutralidade, que é a faixa de temperatura ambiente efetiva dentro da qual o custo fisiológico é mínimo, a retenção da energia da dieta é máxima e o desempenho produtivo esperado é máximo.

Ao longo do tempo surgiram, em diferentes microrregiões, animais perfeitamente adaptados (raças nativas) às condições semiáridas; esta adaptabilidade é medida pela capacidade de produzir nessas condições climáticas, sem perda do desempenho produtivo e sem alterações dos seus parâmetros fisiológicos normais (Santos et al., 2005; Silva et al., 2006; Gomes et al., 2008).

Mesmo se tratando de animais de alta rusticidade, vários fatores podem interferir no desempenho dos caprinos destacando-se, entre eles, os elementos climáticos, como temperatura, umidade relativa do ar e radiação solar, que acarretam alterações nos parâmetros fisiológicos, como na frequência cardíaca, que pode ser utilizada como medida de adaptabilidade da espécie, além da temperatura retal e frequência respiratória (Silva et al., 2010; 2011).

De acordo com Martins Júnior et al. (2007) as raças provenientes do continente africano são mais adaptadas ao semiárido brasileiro que as raças européias, devido à semelhança de clima entre o continente africano e o nordeste brasileiro. A espécie caprina se caracteriza pela sua adaptação às mais diversas condições de ambiente, verificando-se sua ocorrência em quase todas as regiões do mundo. Isto decorre da facilidade dos caprinos se adaptarem às mais diferentes dietas, associadas à sua acentuada capacidade de aclimatação (Santos et al., 2005; Silva et al., 2006; Gomes et al., 2008; Silva et al., 2010). As raças nativas, pela seleção natural a que foram submetidas, suportam o rigor do clima e são adequadas aos sistemas de produção predominantes da região. Apesar dessa habilidade, estudos mostram que o número de animais dos grupos nativos está diminuindo (Ribeiro et al., 2004), em decorrência dos cruzamentos desordenados com raças exóticas.

Objetivou-se, com este trabalho, determinar os índices de conforto térmico e seus efeitos nos parâmetros fisiológicos e desempenho ponderal de caprinos nativos criados em confinamento, na região do cariri paraibano.

\section{Material e MÉTOdos}

O experimento foi realizado na Unidade de Pesquisa em Pequenos Ruminantes, pertencente ao Centro de Ciências Agrárias da Universidade Federal da Paraíba, localizado no município de São João de Cariri, PB, no período de janeiro a abril de 2009. O experimento teve duração de 97 dias, em que os primeiros 21 foram destinados à adaptação dos animais às condições experimentais e 76 para a coleta de dados. O município está localizado na microrregião do Cariri Ocidental, com precipitação anual de $450 \mathrm{~mm}^{2} \mathrm{ano}^{-1}$, Latitude de $7^{\circ} 25^{\prime} \mathrm{Sul}$ e Longitude de $36^{\circ} 30^{\prime}$ oeste, altitude de 450 a $500 \mathrm{~m}$, temperatura média anual de $26^{\circ} \mathrm{C}$ e umidade relativa média anual de $65 \%$.

Foram utilizados 36 caprinos nativos: Moxotó, Azul e Graúna, sendo 12 animais de cada grupo genético, com peso inicial médio de 14,6 $\pm 1,7 \mathrm{~kg}$, todos machos não castrados, distribuídos aleatoriamente em 4 galpões abertos, com baias individuais, cobertos com telhas de cerâmica e piso de chão batido, sentido leste-oeste.

A ração fornecida aos animais foi composta de palma forrageira, feno de buffel e concentrados à base de milho em grão, farelo de soja e suplemento mineral, na forma de mistura completa e formulada com base no NRC (1981), de maneira a proporcionar ganho diário de $150 \mathrm{~g}$ para animais de $15 \mathrm{~kg}$ de peso vivo. $\mathrm{O}$ arraçoamento dos animais foi realizado à vontade, duas vezes ao dia, às 8 e $16 \mathrm{~h}$. A relação volumoso:concentrado foi de 47:53. O controle ponderal dos animais foi realizado semanalmente em balança apropriada para caprinos, sempre pela manhã, antes do arraçoamento.

Durante a fase experimental as variáveis coletadas no interior do galpão foram as seguintes: temperatura de bulbo seco (Tbs), temperatura de bulbo úmido (Tbu), temperatura de globo negro (Tgn), velocidade do vento (Vv), umidade relativa do ar (UR), coletados a cada minuto, ao longo das $24 \mathrm{~h}$, por sensores acoplados a um sistema eletrônico de aquisição de dados, composto de um módulo de medição e de controle da marca Campbell, modelo CR1000. Os sensores da estação automática foram fixados a nível do centro de massa dos animais $(0,7 \mathrm{~m}$ de altura).

Obteve-se a temperatura de globo negro através de sensores instalados no centro do globo negro, com $5 \mathrm{~mm}$ de espessura e $15 \mathrm{~cm}$ de diâmetro, enegrecido com tinta preta de alta absortividade, em cujo centro se encontra um sensor de temperatura que fornece a indicação dos efeitos combinados da temperatura, velocidade do ar e da radiação.

Os valores dos índices de conforto térmico foram determinados a partir dos dados observados no período das 6 às $18 \mathrm{~h}$, com intervalo de $3 \mathrm{~h}$. 
Para o cálculo do índice de temperatura do globo negro e umidade (ITGU) utilizou-se a fórmula sugerida por Buffington et al. (1977), expressa na Eq. (1).

$$
\mathrm{ITGU}=\operatorname{Tgn}+0,36 \mathrm{Td}-330,08
$$

em que Tgn é a temperatura de globo negro e Td é a temperatura de ponto de orvalho, ambas calculadas em $\mathrm{K}$.

Para o cálculo do índice de temperatura e umidade (ITU), utilizou-se a expressão apresentada na Eq. (2):

$$
\mathrm{ITU}=\mathrm{Tgn}+0,36 \mathrm{Td}-330,08
$$

em que Ta é a temperatura do ar e Td é a temperatura de ponto de orvalho, ambas calculadas em $\mathrm{K}$.

A carga térmica radiante (CTR), calculada dentro do aprisco pela expressão apresentada na Eq. (3), citada por Esmay (1969).

$$
\mathrm{CTR}=\mathrm{s}(\mathrm{TRM})^{4}
$$

A CTR é dada em W m ${ }^{-2}$; s é a constante de Stefan-Boltzman, $\left(5,67 \cdot 10^{-8} \mathrm{~W} \mathrm{~m}^{-2} \cdot \mathrm{K}^{-1}\right)$ e TRM é a temperatura radiante média, $\mathrm{K}$

A temperatura radiante média (TRM) é a temperatura de uma circunvizinhança, considerada uniformemente negra, para eliminar o efeito da reflexão com a qual o corpo troca calor com o meio. Pode ser obtida por meio da expressão apresentada na Eq. (4).

$$
\mathrm{TRM}=100\left[2,5 \mathrm{~V}^{1 / 2}(\mathrm{Tgn}-\mathrm{Tbs})+(\operatorname{Tgn} / 100)^{4}\right]^{1 / 4}
$$

em que a TRM é dada em $\mathrm{K}$ e V é a velocidade de vento, $\mathrm{m} \mathrm{s}^{-1}$

Os índices fisiológicos foram medidos a cada $3 \mathrm{~h}$, das 6 às $18 \mathrm{~h}$, três vezes por semana, sendo coletadas a temperatura retal (TR), a frequência respiratória (FR) e a temperatura superficial (TS).

Obteve-se a temperatura retal com a introdução de um termômetro clínico veterinário, com escala até $44{ }^{\circ} \mathrm{C}$, diretamente no reto do animal, a uma profundidade de $5 \mathrm{~cm}$, permanecendo pelo tempo de $2 \mathrm{~min}$. A frequência respiratória foi medida por meio da auscultação indireta das bulhas, com o auxílio de um estetoscópio flexível, a nível da região torácica, contando-se o número de movimentos durante $20 \mathrm{~s}$; este valor foi então multiplicado por três obtendo-se, daí, a quantidade de movimentos por minuto. Para obtenção da temperatura superficial utilizou-se um termômetro infravermelho cujas leituras foram realizadas na cabeça, no costado e nas pernas dos animais, além de utilizada a média das três temperaturas, para o cálculo da TS.

O delineamento estatístico foi o inteiramente casualizado (DIC) com arranjo fatorial 3 x 5 (três raças e 5 horários de observação). Os dados foram avaliados por meio de análise de variância e, quando significativos, foram comparados pelo teste de Tukey a 5\% de probabilidade. Para análise da correlação entre os parâmetros fisiológicos (FR, TR e TS) e os ambientais, utilizaram-se o índice de temperatura de globo negro e a umidade (ITGU), por ser o índice que melhor representa o conforto e/ou desconforto dos animais.

\section{RESULTADOS E DISCUSSÃO}

As médias das variáveis climáticas e índices ambientais, temperatura máxima e mínima (Tmáx e Tmin), temperatura do ar (TA), temperatura de globo negro (TGN), umidade relativa do ar (UR), velocidade do vento (Vv), índice de temperatura do globo negro e umidade (ITGU) e carga térmica radiante (CTR) nos diferentes horários pesquisados, estão apresentados na Tabela 1, na qual se observa diferença significativa $(\mathrm{P}<0,05)$ entre os horários, em todas as variáveis.

Tabela 1. M édias das variáveis climáticas temperatura do ar (TA umidade relativa do ar (UR), velocidade do

\begin{tabular}{|c|c|c|c|c|c|}
\hline Horas & $\begin{array}{c}\text { TA } \\
(\because-C)\end{array}$ & $\begin{array}{l}\text { UR } \\
\text { (\%) }\end{array}$ & $\begin{array}{c}\mathrm{Vv} \\
\left(\mathrm{m} \mathrm{s}^{-1}\right)\end{array}$ & ITGU & $\begin{array}{c}\text { CTR } \\
\left(\mathrm{W} \mathrm{\textrm {m } ^ { - 2 }}\right)\end{array}$ \\
\hline 3 & $19,9 \mathrm{~g}$ & $88,1 \mathrm{a}$ & $1,0 \mathrm{~b}$ & $69,8 \mathrm{f}$ & $464,9 \mathrm{c}$ \\
\hline 6 & $22,8 \mathrm{fg}$ & $71,1 \mathrm{~b}$ & $1,7 \mathrm{a}$ & $73,2 d$ & $507,6 b$ \\
\hline 9 & $26,9 \mathrm{~d}$ & $55,1 \mathrm{e}$ & $1,6 \mathrm{a}$ & $77,4 \mathrm{c}$ & $533,7 \mathrm{a}$ \\
\hline 12 & $31,1 b$ & $40,9 \mathrm{~g}$ & $1,6 \mathrm{a}$ & $80,4 \mathrm{~b}$ & $538,7 \mathrm{a}$ \\
\hline 15 & $33,1 \mathrm{a}$ & $37,1 \mathrm{~h}$ & $0,7 \mathrm{c}$ & $82,9 a$ & $547,2 \mathrm{a}$ \\
\hline 18 & $28,6 \mathrm{c}$ & $50,5 f$ & $0,9 c$ & $75,8 d$ & $466,2 \mathrm{C}$ \\
\hline 21 & $23,9 \mathrm{e}$ & $64,3 d$ & $0,8 \mathrm{c}$ & $71,0 \mathrm{e}$ & $438,7 d$ \\
\hline 0 & 23,2 ef & $68,8 \mathrm{c}$ & $1,1 \mathrm{~b}$ & 70,3 ef & $432,3 d$ \\
\hline Média & 26,2 & 59,5 & 1,2 & 75,4 & 496,4 \\
\hline
\end{tabular}
vento $(\mathrm{Vv})$, índice de temperatura de globo e umidade (ITGU) e carga térmica radiante (CTR), nos diferentes horários pesquisados

Médias seguidas de mesma letra na coluna não diferem a $5 \%$ de probabilidade pelo teste de Tukey

Com base nas temperaturas ao longo do dia, nota-se que a temperatura do ar apresentou acréscimo até as $15 \mathrm{~h}$, quando atingiu seu valor máximo $\left(33,1^{\circ} \mathrm{C}\right)$; a partir de então, ocorreu decréscimo e a temperatura ambiente atingiu o valor mínimo $\left(19,9^{\circ} \mathrm{C}\right)$ às $3 \mathrm{~h}$. As temperaturas das 12 e $15 \mathrm{~h}$ se mantiveram acima da zona de conforto térmico (ZCT) para caprinos que, segundo Baêta \& Souza (2010), variam de 20 a $30^{\circ} \mathrm{C}$; entretanto, esses animais não ultrapassaram a temperatura crítica superior, que é de $35^{\circ} \mathrm{C}$. A temperatura mínima observada teve valor um pouco abaixo da ZCT, ou seja, de $19,9^{\circ} \mathrm{C}$. As temperaturas das $6,9,18,21$ e 00 h se mantiveram dentro da ZCT, sendo que as temperaturas dos horários das 21 e 00 h não diferiram estatisticamente entre si, assim como as temperaturas de 00 e 6 $\mathrm{h}(\mathrm{P}<0,05)$.

No semiárido brasileiro é comum que, nos horários mais quentes do dia, a temperatura permaneça acima da ZCT para caprinos; todavia, caprinos das raças nativas têm expressado bom desempenho produtivo e reprodutivo, devido ao processo adaptativo à região semiárida, desenvolvido ao longo de sua formação, mesmo em condições consideradas acima da zona de conforto (Martins Júnior et al., 2007; Gomes et al., 2008; Silva et al., 2010), fato este extremamente positivo para a raça e indicativo da necessidade de redefinição quanto aos parâmetros de adaptabilidade para as raças nativas do semiárido nordestino.

Resultados semelhantes aos deste trabalho obtiveram Santos et al. (2005) e Silva et al. (2006), que relatam valores de temperatura ambiente fora da ZCT nos horários mais quentes do dia, com valores de 33,7 e $32,0{ }^{\circ} \mathrm{C}$, respectivamente, no período da tarde. 
Em relação à umidade relativa do ar (UR), os dados variam em função dos diferentes horários, sendo superiores pela manhã, decrescendo nos horários da tarde e voltando a subir durante a noite. Segundo Baêta \& Sousa (2010), a umidade relativa ideal para a criação de animais domésticos, deve estar entre 50 e $70 \%$. Nos horários das 3 e $6 \mathrm{~h}$, os valores da UR se mantiveram acima da ZCT com valores de 88,1 e 71,1\%, respectivamente. Nos horários das 12 e 15 h, os valores da UR se mantiveram abaixo do recomendado, apresentando valores de 40,9 e 37,1\%. Valores menores de UR nos horários mais quentes estão associados ao aumento da temperatura do ar. Nos horários das 9, 18, 21 e 00 h, esses valores estão dentro da ZCT. Resultados semelhantes foram encontrados por Gomes et al. (2008), em trabalho com caprinos Moxotó, no semiárido nordestino, ao encontrarem valores de 80 e $41,1 \%$ nos períodos da manhã e tarde, respectivamente, para UR do ar.

Em relação ao ITGU, Silva et al. (2006) observaram, em estudos com caprinos no semiárido paraibano, ITGU no turno da tarde de 84,9; este acontecimento não caracterizou situação de perigo por parte dos caprinos mestiços de Anglo-nubiano, uma vez que a TR dos animais se encontrou dentro da normalidade, com médias de $39,2^{\circ} \mathrm{C}$, demonstrando não estar havendo estocagem de calor pelos animais. Pode-se constatar, então, que das 21 às $6 \mathrm{~h}$ o ITGU mostrou-se confortável para os caprinos, resultado que se deve principalmente à menor temperatura do ar nesses horários. No horário das $3 \mathrm{~h}$ constatouse o menor valor de ITGU $(69,8)$.

Nos horários de TA mais elevada (12 e 15 h) também foram encontrados maiores valores de ITGU (80,4 e 82,9, respectivamente), sendo o horário das $15 \mathrm{~h}$ considerado, neste estudo, o mais crítico. Apesar do elevado valor do ITGU das 15 $\mathrm{h}$, este ficou aquém dos valores encontrados por Santos et al. (2005), Silva et al. (2006) e Gomes et al. (2008), que trabalharam com caprinos no semiárido nordestino e encontraram valores de ITGU no período da tarde de 85,$5 ; 85,1$ e 85,9 , respectivamente.

De acordo com os valores médios da carga térmica radiante (CTR), descritos na Tabela 2, observa-se diferença significativa a $5 \%$ de probabilidade, sendo que o valor máximo foi verificado no horário das $15 \mathrm{~h}\left(547,2 \mathrm{~W} \mathrm{~m}^{-2}\right)$ o qual não diferiu

Tabela 2. M édias da frequência respiratória FR (mov/ min) temperatura retal $\left({ }^{\circ} \mathrm{C}\right)$ e temperatura superficial $\left({ }^{\circ} \mathrm{C}\right)$ dos animais das raças M oxotó, Azul e G raúna, nas raças e nos diferentes horários pesquisados

\begin{tabular}{|c|c|c|c|}
\hline & $\begin{array}{l}\text { Frequência } \\
\text { respiratória } \\
\left(\mathrm{mov} \mathrm{min}^{-1}\right)\end{array}$ & $\begin{array}{l}\text { Temperatura } \\
\text { retal }\left({ }^{\circ} \mathrm{C}\right)\end{array}$ & $\begin{array}{c}\text { Temperatura } \\
\text { superficial }\left({ }^{\circ} \mathrm{C}\right)\end{array}$ \\
\hline $\begin{array}{l}\text { Azul } \\
\text { Moxotó } \\
\text { Graúna }\end{array}$ & $\begin{array}{l}35,0 \mathrm{c} \\
42,8 \mathrm{a} \\
39,2 \mathrm{~b}\end{array}$ & $\begin{array}{l}\text { Raças } \\
38,7 \text { ab } \\
38,5 \mathrm{~b} \\
38,8 \mathrm{a}\end{array}$ & $\begin{array}{l}33,0 \mathrm{a} \\
32,4 \mathrm{a} \\
33,1 \mathrm{a}\end{array}$ \\
\hline $\begin{array}{l}6 \mathrm{~h} \\
9 \mathrm{~h} \\
12 \mathrm{~h} \\
15 \mathrm{~h} \\
18 \mathrm{~h}\end{array}$ & $\begin{array}{l}28,0 d \\
35,6 c \\
45,2 d \\
50,8 d \\
35,4 c\end{array}$ & $\begin{array}{c}\text { Horários (ITGU) } \\
37,4 \mathrm{c} \\
38,6 \mathrm{~b} \\
38,9 \mathrm{ab} \\
39,2 \mathrm{a} \\
39,1 \mathrm{a}\end{array}$ & $\begin{array}{l}27,0 \mathrm{c} \\
32,8 \mathrm{~b} \\
36,4 \mathrm{~b} \\
36,9 \mathrm{a} \\
32,0 \mathrm{~b}\end{array}$ \\
\hline
\end{tabular}

Médias seguidas de mesma letra minúscula na coluna não diferem a $5 \%$ de probabilidade pelo teste de Tukey estatisticamente dos valores das 9 e $12 \mathrm{~h}\left(533,7\right.$ e 538,7 $\left.\mathrm{W} \mathrm{m}^{-2}\right)$. A CTR das 21 e $00 \mathrm{~h}$ (438,7 e 423,3 $\mathrm{W} \mathrm{m}^{-2}$, respectivamente) não diferiu entre si e foram os mais baixos. Em trabalhos realizados no semiárido paraibano Oliveira et al. (2005) e Gomes et al. (2008), encontraram valores de CTR superiores aos descritos neste trabalho com valores máximos de 596,0 e 632,7 W m², respectivamente.

A análise de variância não revelou interação $(\mathrm{P}>0,05)$ entre os fatores estudados, raças e horários. A frequência respiratória e a temperatura retal foram influenciadas $(\mathrm{P}<0,05)$ por ambos os fatores. A variável temperatura superficial só foi influenciada (P > 0,05) pelo fator horário. Na análise de correlações de Pearson, verificou-se haver correlação significativa $(\mathrm{P}<0,001)$ de 69,35 e 76\%, positiva, das variáveis, FR, TR e TS, respectivamente, com o ITGU.

As médias da frequência respiratória (FR), e sua correlação com o ITGU, apresentaram diferença significativa $(\mathrm{P}<0,05)$, diferindo entre as raças e na maioria dos horários pesquisados (Tabela 2). Entre as raças notou-se que os maiores valores da FR foram verificados para a Moxotó, seguida da Graúna e o menor valor foi encontrado para a Azul, sendo que essas médias ficaram acima da ideal para caprinos que, segundo Dukes \& Swenson (1996), é considerada normal quando apresenta valor médio de $15 \mathrm{mov} \mathrm{min}^{-1}$, variando entre 12 e $25 \mathrm{mov} \mathrm{min}^{-1}$, valores esses passíveis serem influenciados pelo trabalho muscular, temperatura ambiente, ingestão de alimentos, gestação, idade e tamanho dos animais.

Esta diferença nos valores da FR pode estar associada à genética dos animais que, mesmo tendo passado por processos de seleção semelhantes, podem utilizar os mecanismos de termólise diferentes. Santos et al. (2005) e Silva et al. (2006) também observaram, avaliando a adaptabilidade de caprinos exóticos e nativos no semiárido paraibano, diferenças entre as raças na FR e que isto pode ocorrer em razão da alimentação, temperatura ambiente, idade e raça, sendo que os animais apresentaram folículo piloso, número de glândulas sebáceas e sudoríparas diferentes (Silva et al., 2010).

Na correlação entre os horários, analisada através do ITGU, observa-se que os menores valores da FR foram encontrados às $6 \mathrm{~h}\left(28 \mathrm{mov} \mathrm{min}^{-1}\right)$, elevando-se com os horários, atingindo o maior valor às $15 \mathrm{~h}\left(50,8 \mathrm{mov} \mathrm{min}^{-1}\right)$, quando começaram a decrescer novamente. Referidos altos valores nos horários das 12 e 15 h, estão associados a um aumento da radiação solar e à elevação da TA, ITGU e CTR, com umidade relativa do ar abaixo do valor ideal, que é entre 50 e $70 \%$ (Baêta \& Sousa, 2010).

Durante o período mais quente do dia os animais se encontravam fora da zona de conforto térmico, com TA de 33,1 ${ }^{\circ} \mathrm{C}$ e ITGU de 82,9. Quando ocorre elevação acentuada na temperatura ambiente, os mecanismos termorreguladores são acionados, acarretando um aumento da perda de calor na forma insensível, através da sudorese e aumento da FR. Os valores encontrados neste experimento para FR foram inferiores aos indicados por Gomes et al. (2008) que, trabalhando com caprinos Moxotó no semiárido, encontraram valores médios de FR às 15 h, de 70,4 mov min ${ }^{-1}$ além de inferiores aos obtidos por Souza et al. (2005), que os caprinos mestiços apresentaram valores de FR no período da tarde, de 60,6 mov $\mathrm{min}^{-1}$. 
Para a temperatura retal (TR) média dos animais houve diferença significativa $(\mathrm{P}<0,05)$ entre os horários e as raças Graúna e Moxotó, sendo que a Azul não diferiu entre as outras raças. A TR dos animais ficou dentro da normalidade para a espécie em que, segundo Dukes \& Swenson (1996) a temperatura retal normal para caprinos adultos varia de $38,5^{\circ} \mathrm{C}$ a $39,7^{\circ} \mathrm{C}$. Esta diferença na TR entre as raças também foi observada por Silva et al. (2010), em trabalhos com caprinos no semiárido paraibano.

Correlacionando os valores da TR com o ITGU, nota-se que ela tende a aumentar gradativamente entre os horários, atingindo valores máximos nos horários das 15 e 18 h e valores mínimos às $6 \mathrm{~h}$; este aumento da TR e controle da homeotermia nesses horários está associado ao ITGU, que entre esses horários esteve mais elevado, influenciado pela temperatura do ar que atingiu valor máximo de $33,1^{\circ} \mathrm{C}$ no horário das $15 \mathrm{~h}$, associado com uma UR mais baixa $(37,1 \%)$ e com CTR de 547,2 $\mathrm{W} \mathrm{m} \mathrm{m}^{2}$, ocasionado situação de desconforto térmico, por maior incidência de radiação solar à tarde.

Gomes et al. (2008) encontraram, trabalhando com caprinos nativos, resultados semelhantes visto que nos horários da manhã os valores foram menores para TR quando comparados com os valores da tarde, fato este atribuído às diferenças das condições climáticas. A TR é o resultado entre a energia térmica produzida e a energia térmica dissipada. Um aumento da TR significa que o animal está estocando calor e se não houver dissipação, o estresse por calor se manifesta (Santos et al., 2006).

Considerando a elevação dos fatores climáticos, vê-se que os animais não apresentaram TR fora dos padrões normais (até $40{ }^{\circ} \mathrm{C}$ ) nas variações e condições climáticas de TA, UR e CTR, a que estavam submetidos; tal comportamento sugere que o sistema termorregulador foi usado com eficiência, uma vez que a TR dos animais se encontra dentro da normalidade, demonstrando não estar havendo estocagem de calor, sendo a temperatura do ar um parâmetro climático importante na estimativa do efeito do clima sobre o comportamento fisiológico do animal (Silva et al., 2006).

Em relação à temperatura superficial (TS) dos animais, evidenciou-se que não houve diferença significativa $(P>0,05)$ entre as raças, mas variou significativamente $(\mathrm{P}<0,05)$ entre os horários do dia (Tabela 2); A TS ficou mais elevada a partir das $9 \mathrm{~h}$, atingindo valores máximos às $15 \mathrm{~h}$. Esta variação na TS está associada à oscilação dos fatores climáticos, sendo que, nos horários das 12 e 15 h, considerados horários críticos, as variáveis ambientais se encontravam fora da zona de conforto térmico. Referidos resultados estão de acordo com os citados por Gomes et al. (2008) e Silva et al. (2006), que trabalhando com caprinos nativos no semiárido paraibano, encontraram valores de temperatura superficial mais elevados no período da tarde, quando comparados com o período da manhã.

Em geral, o fato de que o pelame escuro apresente maior absorção e menor reflexão da radiação térmica é acatado, resultando em maior estresse pelo calor para os animais; apesar disto, tem-se demonstrado que os pelames claros apresentam maior penetração da radiação solar que os escuros (Silva et al., 2001). Maia et al. (2003) citam que a quantidade de radiação efetivamente transmitida através da capa do pelame depende não só da cor mas também do alto grau de sua estrutura física, sobretudo do número de pelos por unidade de área.

É oportuno identificar que os caprinos da raça Graúna apresentam pelame de cor mais escura que as raças Moxotó e Azul; entretanto, esta característica não foi decisiva em relação à temperatura da superfície, de vez que as raças apresentaram temperaturas superficiais semelhantes. Esta variável pode ter sofrido influência do tipo de abrigo no qual os animais estavam confinados, sendo que as baias nas quais os animais estavam apresentavam área coberta, na sombra, e outra não-coberta, exposta ao sol, onde os animais podiam circular livremente; dependendo do local em que o animal se encontrava no momento da avaliação, este pode ter influenciado na TS.

$\mathrm{O}$ peso médio dos animais (Tabela 3 ), no final do experimento, não diferiu significativamente $(\mathrm{P}<0,05)$, que foi de $16.6 \pm 1,7 \mathrm{~kg} / \mathrm{PV}$; entretanto, a raça Graúna apresentou maior ganho de peso diário $(64,1 \mathrm{~g})$ e maior ganho de peso do período $(4,9 \mathrm{~kg})$, em que o consumo de matéria seca diferiu estatisticamente $(\mathrm{P}<0,05)$ entre os animais; os animais Graúna foram os que mais consumiram, seguidos do Moxotó e Azul. Correlacionando o consumo médio de matéria seca com o consumo médio de água entre as raças, observa-se que na raça Azul foi de 1,0:2,07, na raça Graúna, de 1,0:1,79 e na Moxotó, de 1,0:1,52, com média de 1,0:1,77.

Tabela 3. Peso inicial (PI), peso final (PF), média de peso vivo (MP), ganho de peso diário (GPD) e ganho de peso do período (GPP)

\begin{tabular}{clllll}
\hline \multirow{2}{*}{ Raças } & \multicolumn{1}{c}{$\mathbf{P I}$} & \multicolumn{1}{c}{$\mathbf{P F}$} & $\mathbf{M P}$ & $\mathbf{G P P}$ & $\mathbf{G P D}$ \\
\cline { 2 - 5 } & \multicolumn{4}{c}{$\mathbf{k g}$} & $\mathbf{g}$ \\
Moxotó & $14,4 \mathrm{a}$ & $18,4 \mathrm{~b}$ & $16,4 \mathrm{a}$ & $4,0 \mathrm{~b}$ & $52,6 \mathrm{~b}$ \\
Azul & $14,8 \mathrm{a}$ & $17,9 \mathrm{~b}$ & $16,4 \mathrm{a}$ & $3,1 \mathrm{~b}$ & $41,2 \mathrm{~b}$ \\
Graúna & $14,7 \mathrm{a}$ & $19,6 \mathrm{a}$ & $17,2 \mathrm{a}$ & $4,9 \mathrm{a}$ & $64,1 \mathrm{a}$ \\
Média & 14,6 & 18,6 & 16,6 & 4,0 & 52,6 \\
\hline Médias seguidas de mesma letra na coluna não diferem a 5\% de probabilidade pelo teste de Tukey
\end{tabular}

Esses valores ficaram abaixo do descrito por Valverde (1999), que cita uma relação de 1:4; este fato também pode ser justificado pelo tipo de volumoso fornecido aos animais, composto de palma forrageira que, segundo Vieira et al. (2006), proporciona redução no consumo de água pelos caprinos, em função deste alimento possuir alto teor de água. Outro fator que deve ser destacado diz respeito ao processo de seleção natural em que os caprinos nativos do semiárido brasileiro passaram a consumir menos água, maximizando sua utilização.

Os resultados do ganho de peso diário desse experimento corroboram com os encontrados por Malafaia et al. (2004) os quais, utilizando dois níveis de suplementação mineral na alimentação de caprinos 3/4 Boer-Saanen, não observaram diferença significativa entre os tratamentos, com média de ganho de peso diário de 53,2 g.

Referidos resultados ficaram aquém dos encontrados por Dias et al. (2010) que, trabalhando com cabritos mestiços Anglonubiano no nordeste brasileiro, com peso vivo médio de $20 \mathrm{~kg}$, utilizando farelo grosso de trigo em substituição ao milho na dieta dos animais, constataram uma média de ganho de peso diário de 106,5 g. Silva \& Araújo (2000) também encontraram, com caprinos mestiços de Pardo Alpino, 
Anglonubiano e Moxotó, no semiárido nordestino, resultados superiores aos deste experimento, com média geral de ganho de peso diário de $133 \mathrm{~g}$.

\section{CONCLUSÕES}

1. Os índices de conforto ambiental ficaram elevados a partir das 12 h; no entanto, os caprinos das raças Moxotó, Azul e Graúna conseguem manter a temperatura retal dentro dos limites normais, porém com aumento da frequência respiratória.

2. Os animais da raça Graúna apresentam maior ganho de peso diário e maior ganho de peso do período experimental, quando comparados com os das outras raças estudadas.

\section{LITERATURA CITADA}

Bacari Júnior, F.; Gayão, A. L. B. A.; Gottschalk, A. F. Metabolicrate and some physiological and production response f lactating Saanen goats during thermal stress. In: International Congress of biometeorology, 14, 1996, Ljubljana, Slovenia. Anais... Ljubljana: ISB, 1996, p.119-122.

Baêta, F. C.; Souza, C. F. Ambiência em edificações rurais Conforto animal. 2.ed. Viçosa: UFV. 2010. 246p.

Buffington, D. E.; Collazo Arocho, A.; Canton, G. H. Pitt. globehumidity index (BGHI) as a comfort equation for dairy cows. Transaction of the ASAE, v.24, p.711-714, 1977.

Dias, A. M. A.; Batista, A. M. V.; Carvalho, F. F. R.; Guim, A.; Silva, G.; Silva, A. C. Consumo e digestibilidade dos nutrientes e desempenho de caprinos recebendo farelo grosso de trigo na dieta em substituição ao milho. Revista Brasileira de Zootecnia, v.39, p.831-836, 2010.

Dukes, H. H.; Swenson, H. J. Fisiologia dos animais domésticos. 11.ed. Rio de Janeiro: Guanabara, 1996. 856p.

Esmay, M. L. Principles of animal environment, 2.ed. Wastport: CT. AVI, 1969.325p.

Gomes, C. A. V.; Furtado, D. A.; Medeiros, A. N.; Silva, D. S.; Pimenta Filho, E. C.; Lima Júnior, V. Efeito do ambiente térmico e níveis de suplementação nos parâmetros fisiológicos de caprinos Moxotó. Revista Brasileira de Engenharia Agrícola eAmbiental, v.12, p.213-219, 2008.

Maia, A. S. C.; Silva, R. G.; Bertipaglia, E. C. A.; Características do pelame de vacas Holandesas em ambiente tropical: Um estudo genético e adaptativo. Revista Brasileira de Zootecnia, v.32, p.843-853, 2003.

Malafaia, P.; Pimentel, V. A.; Freitas, K. P.; Coelho, C. D.; Brito, M. F.; Peixoto, P. V. Desempenho ponderal, aspectos econômicos, nutricionais e clínicos de caprinos submetidos a dois esquemas de suplementação mineral. Pesquisa Veterinária Brasileira, v.24, p.15-22, 2004.

Martins Júnior, L. M.; Costa, A. P. R.; Ribeiro, D. M. M.; Turco, S. H. N.; Muratori, M. C. S. Respostas fisiológicas de caprinos Boer e Anglo-Nubiana em condições climáticas de Meio-norte do Brasil. Revista Caatinga, v.20, p.1-7, 2007.

NRC - National Research Council. Nutrient requirement of domestics animals. Washington, DC: Nacional Academy Press, 1981. 91p.
Oliveira, F. M. M.; Dantas, R. T.; Furtado, D. A.; Nascimento, J. W. B. do; Medeiros, A. N. Parâmetros de conforto térmico e fisiológicos de ovinos Santa Inês, sob diferentes sistemas de acondicionamento. Revista Brasileira de Engenharia Agrícola Ambiental, v.9, p.631-635, 2005.

Perissionoto, M.; Moura, D. J.; Silva, I. J. O.; Matarazzo, S. V. Influência do ambiente no consumo de água de bebida de vacas leiteiras. Revista Brasileira de Engenharia Agrícola e Ambiental, v.9, p.289-294, 2005.

Ribeiro, M. N.; Gomes Filho, M. A.; Bermejo, J. V. D. Conservação de raças caprinas nativas do Brasil: Histórico, situação atual e perspectivas. Recife: UFRPE, Imprensa Universitária, 2004. $62 \mathrm{p}$.

Santos, F. C. B.; Souza, B. B.; Alfaro, C. E. P.; César, M. F.; Pimenta Filho, E. C.; Acosta, A. A. A.; Santos, J. R. S. Adaptabilidade de caprinos exóticos e naturalizados ao clima semi-arido do nordeste brasileiro. Ciência e Agrotecnologia, v.29, p.142-149, 2005.

Santos, J. R. S.; Souza, B. B.; Souza, W. H.; César, M. F.; Tavares, G. P. Respostas fisiológicas e gradientes térmicos de ovinos das raças Santa Inês, Morada Nova e seus cruzamentos com a raça Dorper às condições do semi-árido nordestino. Ciência e Agrotecnologia, v.30, p.995-1001, 2006.

Silva, C. M. B. A.; Souza, B. B. de; Brandão, P. A.; Marinho, P. V. T.; Benício, T. M. A. Efeito das condições climáticas do semiárido sobre o comportamento fisiológico de caprinos mestiços F1 Saanen x Boer. Revista Caatinga, v.24, p.195199, 2011.

Silva, E. M. N.; Souza, B. B.; Souza, O. B. de; Silva, G. A.; Freitas, M. M. S. de. Avaliação da adaptabilidade de caprinos ao semiárido através de parâmetros fisiológicos e estruturas do tegumento. Revista Caatinga, v.23, p.142-148, 2010.

Silva, F. L. R.; Araújo, A. M. Desempenho produtivo em caprinos mestiços no semi-árido do Nordeste do Brasil. Revista Brasileira de Zootecnia, v.29, p.1028-1035, 2000.

Silva, G. A.; Souza, B. B.; Alfaro, C. E. P.; Silva, E. N. M.; Azevedo, S. A.; Azevedo Neto, J.; Silva, R. M. N. Efeito da época do ano e do período do dia sobre os parâmetros fisiológicos de reprodutores caprinos no semi-árido paraibano. Revista Brasileira de Engenharia Agrícola e Ambiental, v.10, p.903-909, 2006.

Silva, R. G.; Lascala Júnior, N.; Pocay, P. L. B.; Transmissão de radiação ultra violeta através do pelame e da epiderme de bovinos. Revista Brasileira de Zootecnia, v.30, p.1939-1947, 2001.

Souza, E. D.; Souza, B. B.; Souza, W. H.; César, M. F.; Santos, J. R. S.; Tavares, G. P. Determinação dos parâmetros fisiológicos e gradiente térmico de diferentes grupos genéticos de caprinos no semi-árido. Ciência e Agrotecnologia, v.29, p.1-10, 2005.

Valverde, C. C. 250 maneiras de preparar rações balanceadas para caprinos. Viçosa. Aprenda Fácil. 1999. 110p.

Vieira, E. L.; Batista, A. M. V.; Mustafa, A. F.; Araújo, R. F. S.; Soares, P. C.; Ortalani, E. L.; Mori. C. S. Effects of feeding high levels of cactus (Opuntia fícus-indica Mill) cladodes on unirnary and eletrolyte excretions in goat. Livestock Science, v.114, p.159-165, 2006. 